Bol. Acad. peru. leng. 47. 2009 (11-26)

\title{
DICCIONARIOS Y ENCICLOPEDIAS EN EL CONTEXTO CULTURAL DEL SIGLO XVIII
}

\author{
DICTIONNAIRES ET ENCYCLOPÉDIES DANS LE \\ CONTEXTE CULTUREL DU XVIIIème SIÈCLE
}

\section{DICTIONARIES AND ENCYCLOPAEDIAS IN THE 18TH CENTURY CULTURAL CONTEXT}

\author{
Gloria Cristina Flórez \\ Universidad Nacional Mayor de San Marcos \\ "Un buen diccionario debe cambiar \\ el modo de pensar común”. \\ Paul Hazard
}

Resumen:

El siglo XVIII ha dado lugar a importantes cambios en la política, la economía y las sociedades en Europa occidental. Entre esos cambios destacan los culturales los que se proyectan hasta la actualidad, en especial lo concerniente al vocabulario, imágenes y comportamientos. Nos interesa presentar la extraordinaria ampliación del horizonte cultural, sea en lo correspondiente a la variedad de conocimientos así como su difusión en los diversos grupos sociales. Se busca difundir un saber amplio, variado y actual donde la razón, el progreso, la felicidad, la crítica y la verdad tengan importancia fundamental: Es necesario utilizar en la divulgación diversos medios como libros, especialmente diccionarios y enciclopedias y contar con el apoyo de las academias y sociedades científicas. 
Résumé:

Le XVIIIème siècle a donné lieu à d'importants changements dans la politique, l'économie et les sociétés d'Europe de l'Ouest. Nous observons donc, jusqu'à aujourd'hui encore, des changements culturels, en particulier dans le domaine du vocabulaire, des images et comportements. Nous voudrions présenter l'extraordinaire élargissement de l'horizon culturel, en termes de variété de connaissances et de sa diffusion au sein des divers groupes sociaux. L'objectif est de diffuser un savoir vaste, varié et actuel où la raison, le progrès, le bonheur, la critique et la vérité jouissent d'une importance fondamentale: il est nécessaire de se baser sur la divulgation de divers moyens tels que les livres, en particulier les dictionnaires et encyclopédies, et de disposer du soutien des académies et sociétés scientifiques.

\begin{abstract}
:
To the modern World, the 18th century represents an era of important economic and political changes and a great impulse to language, imaginery and behavioural studies. Knowledge gets enhanced through the diffusion of a variety of themes linked to reason, progress, happiness, criticism and truth, and different social groups to reach. To this aim it will be necessary to have books, dictionaries and encyclopaedias and the sponsorship of academies and scientific societies.
\end{abstract}

Palabras clave:

Diccionarios; enciclopedias; siglo XVIII.

Mots clés:

Dictionnaires; encyclopédies; XVIIIème siècle.

Key words:

Dictionaries; encyclopedias; 18th century. 


\section{El siglo de las Luces: contexto, ideas y ámbitos de difusión}

Es necesario considerar los antecedentes - próximos y lejanos- del pensamiento y acción del siglo XVIII: la Reforma Protestante y el libre examen, el Renacimiento con su amor al hombre y a la Naturaleza y situaciones ligadas al desarrollo del capitalismo mercantil, la génesis del Estado moderno y los esbozos del "liberalismo", el aporte del cartesianismo y el resurgimiento del espíritu crítico.

Las ideas dieciochescas, en su mayoría no son originales, son reactualizadas y podemos considerarlas como nuevas. No son abundantes pero se citan frecuentemente e impactan a sus lectores, a los cuales tratan de convencer y atraer en su lucha contra lo que consideraba caduco y que debía ser destruido y es una lucha encarnizada por que se enfrenta a un conjunto ideológico sistematizado que no ha sido totalmente desarticulado.

El siglo XVIII se caracteriza asimismo por una extraordinaria ampliación del horizonte cultural, no sólo en cuanto a la variedad de conocimientos sino también de difusión en los diversos grupos sociales. Se trata de hacer conocer lo más posible en el menor tiempo al mayor número de individuos. Se busca difundir un saber amplio, variado, actual y no demasiado profundo que desplace el proporcionado por las decadentes Universidades de la época, apegado a lo tradicional y muy poco práctico.

Es la época del optimismo, se tiene absoluta confianza en las fuerzas humanas las que podrían difundir la cultura, que llevaría al progreso y así lograr la anhelada felicidad. Los filósofos y su público coincidían en querer las aplicaciones prácticas del saber humano más que la formulación de teorías que consideraban inútiles para alcanzar el Progreso y la felicidad. El Estado tiene asignado su papel pues preocupándose por el bienestar de sus súbditos - tanto en lo material como en lo intelectual- facilitaría la labor aprendida.

Una característica que les liga al Renacimiento se presenta en el cosmopolitismo, en el afán de relacionar todo, en la universalidad que se desea conseguir, aunque se limite al continente europeo no solamente en las ideas sino también el deseo de una mayor unión entre los estados 
europeos con la desaparición de fronteras, para poder llegar al ideal de paz y armonía. El cosmopolitismo además de relacionarse con el afán de saber universal se relaciona con otras características de la época, como por ejemplo: el amor a los viajes. ${ }^{1}$

El culto a la razón, soberana universal que permite la obtención de conocimientos útiles y verdaderos, gracias a los cuales se conseguiría progreso en todos los órdenes: moral, material, intelectual. La razón al acudir a la experiencia va a encontrar un fundamento de validez que evitará toda posibilidad de error al someter a comprobación cualquier teoría, permitiendo verificar los resultados de manera inmediata y directa.

En lo referente al naturalismo, es difícil dar una definición adecuada que pueda claramente identificarlo. Esa naturaleza la cual tanto elogian y la cual es entendida por cada uno a su manera, se relaciona con el gusto por la vida campestre, o con el goce sin límites o con una nueva moral, cuyas leyes se identificarían con la ley natural. Es el momento de un humanismo revitalizado el cual coloca al hombre como la preocupación central de la época e interesa sobremanera que alcance la felicidad.

El personaje representativo del Siglo de las Luces es el filósofo que se interesa en la fundamentación de una praxis, lo definiríamos como un hombre honrado que obra en todo por la razón y que une a su espíritu de reflexión, la justicia, las buenas costumbres y las cualidades sociales, según la concepción de Diderot en la Enciclopedia. "Tenemos, antes de existir el término, al escritor comprometido" ${ }^{2}$ ya que participa, sobre todo, en aquellos asuntos de autoridad en los cuales sus ideales son vulnerados como en el caso Calas defendido por Voltaire.

Pero a todo lo antes mencionado debemos preguntarnos iQué objetivos persiguen en el siglo XVIII? En el campo político podemos afirmar que "L'Histoire du siècle résulte d'un combat, parfois d'un dialogue, entre les actes du pouvoir autocratique et les ripostes des hommes indociles" 3 .

1 Se ha designado generalmente al siglo XVIII como el gran siglo del viaje. Jean-Marie Goulemot y Michel Launay, El siglo de las luces, p. 29. Jean Starobinski, L'Invention de la liberté, p. 12. 
Los filósofos buscan ciertos principios reguladores provenientes regularmente de la "diosa soberana", para regir las relaciones entre gobernantes y gobernados. El pensamiento político de la época posee matices de acuerdo al país de origen, pero el elemento común es la importancia que se da a la razón y la libertad.

La Ilustración es un movimiento que comprende los diferentes aspectos de la actividad humana, cuya característica es claramente reformista. Su arma más eficaz contra todo lo establecido va a ser la crítica. Los integrantes de este movimiento, son deudores de los hombres de los siglos anteriores, buscaban la realización de una serie de ideales con los cuales esperan que el hombre "ilustrado" alcance la felicidad. Utilizando, en primer lugar, la razón que se relaciona estrechamente con la Naturaleza, acuden al método de la observación. Gracias a la conjunción de razón y observación podría alcanzarse la verdad.

El nuevo orden ilustrado permitiría alcanzar el ideal de progreso material, moral o intelectual que sintetice los aportes positivos y racionales. Toda esta ideología se relaciona estrechamente con la situación socio-económica de la época, con el progreso de comercio y el desarrollo que estaba logrando la manufactura, actividades que están en manos de la burguesía, principalmente. Aunque no todos los ideólogos de este movimiento pertenezcan a dicho grupo comparten mucho de los ideales burgueses como racionalidad, utilidad, liberalismo. Confían en una monarquía, pero "ilustrada" lleve a cabo las reformas que ellos plantean, basadas en la racionalidad en los diferentes campos de su actividad.

Los medios utilizados para ayudar a la divulgación de los conocimientos son diversos: libros como los Diccionarios, Enciclopedias e igualmente periódicos, gacetas, cartas y muy en especial el papel que desempeñan en esta época ciertos espacios como:

a) Los Salones. Debemos relacionarlos con el papel ejercido por las mujeres en el movimiento espiritual de la época. Tratan de lograr la reunión de personajes relevantes para dar mayor prestigio a sus salones. El de Madame Tencin en la calle Saint Honoré, 
caracterizado sobre todo por las intrigas que allí se desarrollaron y por la acogida dispensada a los extranjeros. El de Madame Geoffrin ubicado también en la calle Saint Honoré, una de las primeras instituciones de Europa -según las palabras de Saint Beuve-. Es importante hacer resaltar su labor como una de las personas que ayuda económicamente a la Enciclopedia.

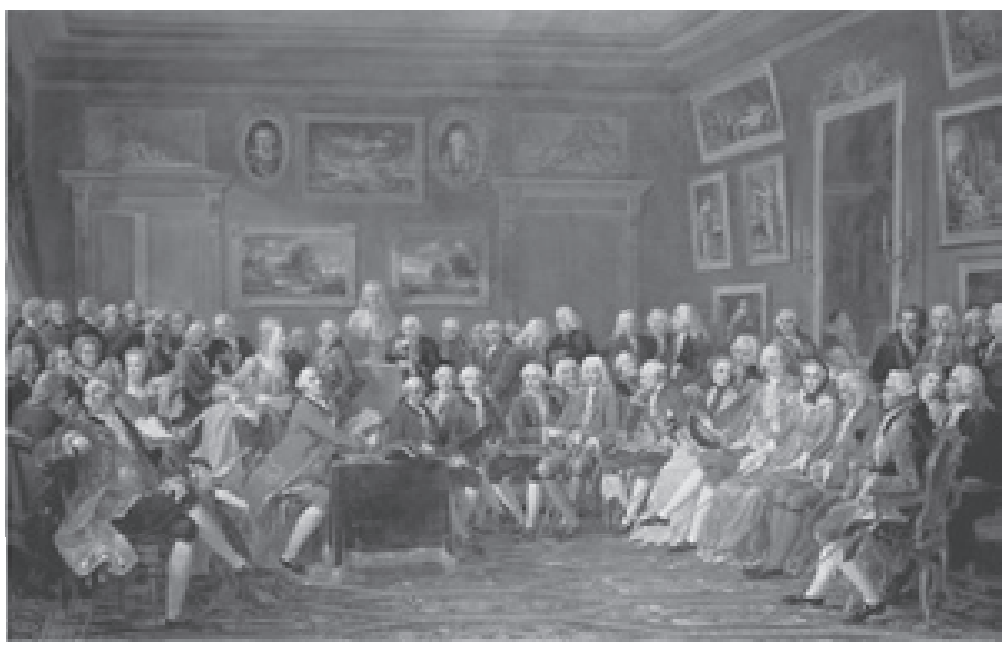

Asimismo, los Cafés cuyo origen se remonta a fines del siglo XVII siendo el más característico el Café Procopio, abierto en 1689 por el noble siciliano Francisco Procope Caltelli y situado al frente de la Comedia Francesa. Fue el embajador turco en Francia quien ayudó a poner de moda estos locales en París que fueron el punto de reunión para intercambiar ideas y noticias de actualidad. 


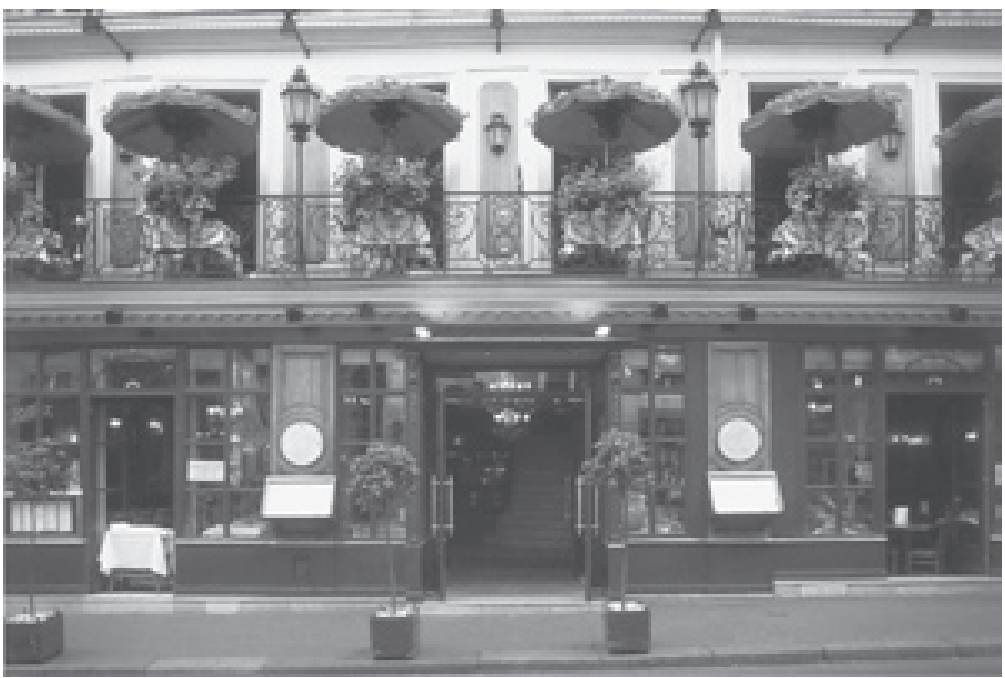

b) Los clubes. El club es una institución de origen inglés, el cual, en sus inicios, designaba a ciertas asociaciones de carácter particular. Tenía un lugar de reunión permanente y fijo, y, generalmente, una finalidad política, literaria o artística. Esta institución va a trasladarse a Francia y también va a tener papel preponderante en la Revolución de 1789. El club de los jacobinos es un buen ejemplo.

Pero especialmente debemos considerar a dos centros intelectuales del siglo XVIII. En primer lugar a:

a) La Sociedad Culta que tuvo como una de sus formas características a la conocida como Sociedad de Amigos del País. Esta asociación tuvo sus orígenes en Francia, donde el interés gubernamental por el apoyo a lo que signifique Ilustración y Luces va a favorecer su difusión en la segunda mitad del siglo.

b) La Academia cuyos antecedentes próximos los encontramos en el siglo XVII. Es una sociedad científica, literaria o artística cuyo fin es perfeccionar la ciencia, el arte, la literatura y el mejoramiento

Bol. Acad. peru. leng. 47(47), 2009 
de los socios en el campo respectivo. Se distingue por su carácter local, por no admitir la intervención de tipo oficial y porque sus miembros pertenecen a la aristocracia y a la alta burguesía, pero cuentan además con miembros corresponsales en otras ciudades del país y del extranjero. Sus actividades se relacionan con el dictado de conferencias, creación de bibliotecas y gabinetes que ayuden a suplir las deficiencias educativas de la época y, por último, la convocatoria de concursos, cuya finalidad era, aparte de estimular el afán de saber, conseguir nuevos miembros para dicha asociación. Estos concursos, aunque teóricamente estaban abiertos para todos los que deseaban participar en ellos, en la práctica estaban limitados a una minoría selecta. La convocatoria se hacía mediante la publicación de los temas del concurso en los principales diarios europeos. Estos concursos prestan doble utilidad: mantienen vivo el interés intelectual e influyen en el pensamiento de la época como en el caso del "Discurso sobre Ciencias y Artes" de Rousseau con el que gana el premio de la Academia de Dijon.

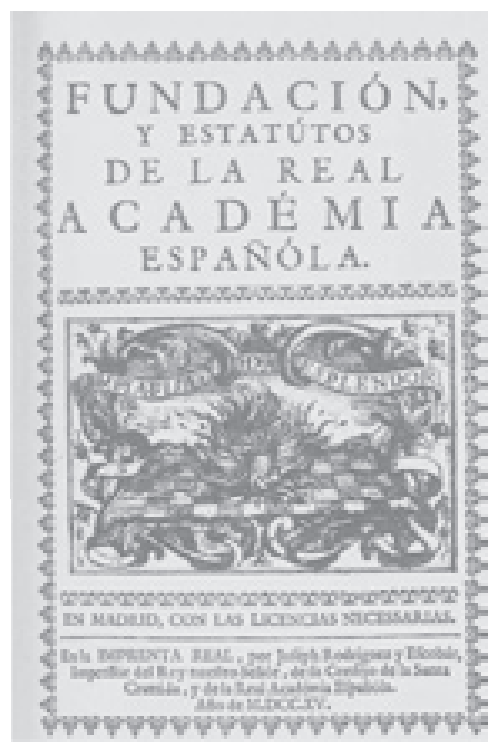




\section{Los medios de difusión}

\section{La Enciclopedia}

Esta vasta obra realizada en el siglo XVIII y considerada la más representativa de la época, la debemos a la iniciativa de los llamados "Philosophes", quienes quisieron, a través de ella, hacer una obra de "ciencia y vulgarización". Es necesario tener en cuenta que durante el siglo XVIII se va a dar un movimiento a nivel europeo que trata de difundir los conocimientos humanos, pero siempre y cuando se trate de "lo nuevo", "lo moderno". Pero no buscaban únicamente lo nuevo, sino todo aquello que fuera útil para ese progreso, aquello que, de alguna forma, fuera de interés y utilidad para el individuo. A lo anterior se unía el deseo de difundir, todo lo que era expresión de su racionalismo.

Lo interesante es que esta obra era el estar destinada a la mayor cantidad posible de público, no especialistas que deseaban una manera fácil y sencilla de adquirir un bagaje cultural, con un mínimo esfuerzo y que se interesaban en los temas de actualidad.

Así cuando en 1721, el cuáquero Ephraim Chambers publica en Londres su Cyclopaedia or Universal Dictionary of Arts and Sciences en dos volúmenes y su éxito es grandioso. Dos editores: Dills y Sellius -inglés y alemán respectivamente-, piensan en la posibilidad de hacer una traducción francesa, la cual imaginan tan exitosa como la original. 


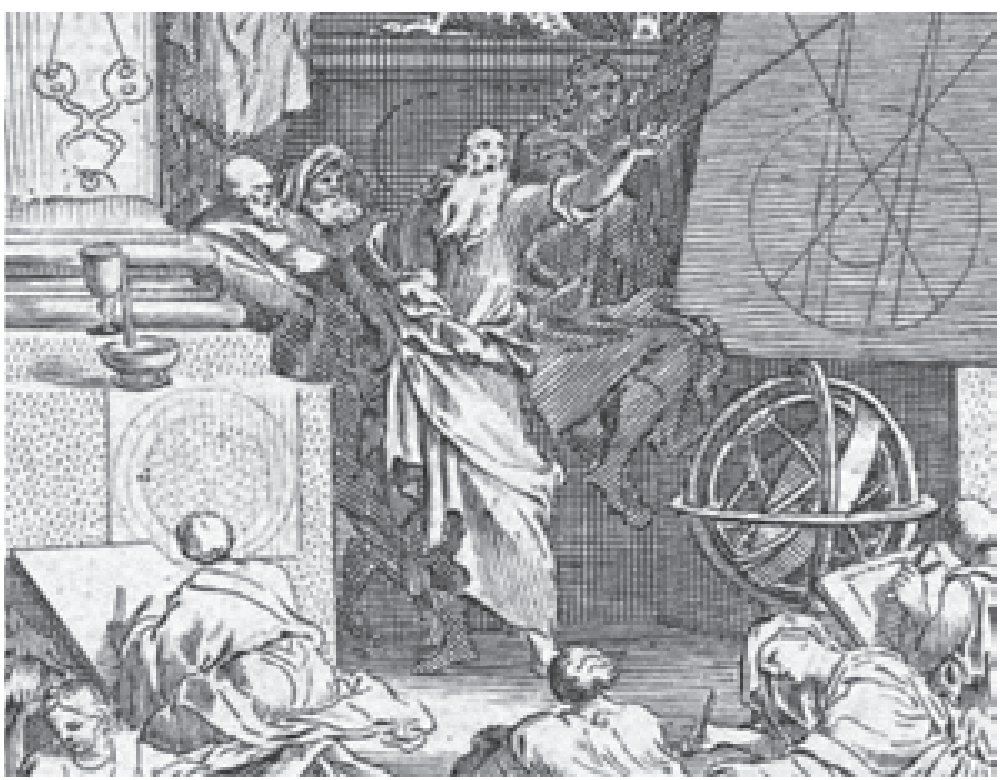

Luego de una serie de vicisitudes se encargará la obra a Diderot quien dice al referirse a la Enciclopedia:

"L'objectif d'une Encyclopédie .....est de rassembler la somme de connaissances éparpillées dans le monde; d'expliquer son plan général à nos contemporains et de les transmettre aux hommes qui nous succéderont sur la terre, de façon à ce que les travaux des siècles passés puissent servir dans les temps futurs, afin que nos descendants, ainsi mieux informés, puissent par conséquent être plus heureux et plus vertueux". ${ }^{4}$

Diderot comparte esa dirección con $\mathrm{D}^{\prime}$ Alambert quien será el encargado de los artículos de matemáticas. En octubre de 1750 un "Prospectus" anuncia la próxima aparición de la obra y los temas que tratará. El primer volumen de la Encyclopédie, ou Dictionnaire raysonné des Sciences des Arts et des Métiers par une Société des Gens de lettres (título

$4 \quad$ Ch. Melchior Bonnet, Les pouvoirs absolus, p. 109. 
completo) aparece el primero de julio del año siguiente. En este volumen es de sumo interés el artículo inicial, "Discours préliminaire", redactado por D'Alembert, en el cual se presenta un cuadro sistematizado de los conocimientos de la época.

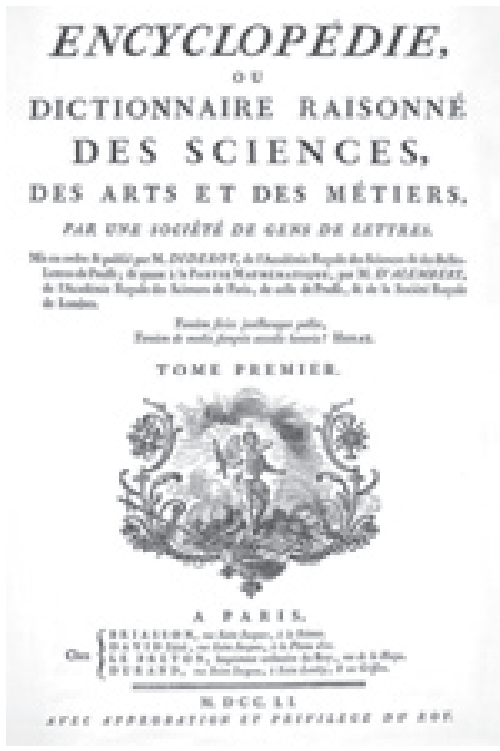

No podemos considerar que participaron en ella todos los autores representativos de la época aunque sí lo hizo un gran número de ellos pero, en gran parte, los autores fueron de poca relevancia. Si bien no se la puede considerar la obra cumbre del siglo XVIII, podemos considerar valedera la afirmación de Paul Hazard "La Enciclopedia es una de las fuerzas representativas de Europa". ${ }^{5}$

Debemos reconocer a la Enciclopedia como una obra interesante desde dos puntos de vista: primero, como manifestación de una época que trata de hacer realidad los deseos dieciochescos así como del espíritu

5 Paul, Hazard, El pensamiento europeo en el siglo XVIII, p. 261.

Bol. Acad. peru. leng. 47(47), 2009 
imperante cuya meta común era conseguir la felicidad, a la cual se llegaba por el camino del progreso humano obtenido a base de la utilización de los conocimientos científicos y técnicos. Desde este ángulo, es importante compendiar las diferentes ramas del saber humano en función de su utilidad a la humanidad, ese compendio vendría a ser lo que tantas veces se ha repetido: una Suma cuyo significado sería similar al de la obra de Santo Tomás de Aquino para la teología medieval, sólo que el objetivo era totalmente diferente.

En segundo lugar, la Enciclopedia es la representante de una clase entonces en pleno ascenso social, la burguesía. Ella necesitaba dar a conocer sus planteamientos socio-económicos, oponiéndose a la nobleza, la cual en muchas oportunidades la mantenía marginada, impidiéndole el ascenso social que tanto deseaban y tratan en todo momento de luchar contra esas limitaciones. Es un nuevo orden el que buscan, un orden "burgués" de acuerdo a sus intereses y naturalmente muchas de las ideas que alimenta ese grupo encuentran su expresión en la obra que estudiamos.

Es importante, por lo tanto, tener en cuenta ambos factores para aquilatar mejor el significado y la influencia de la obra. El espíritu del siglo XVIII le da al hombre una confianza total en sí mismo, en su razón y en su capacidad para poder ser feliz. Así se da un vuelco en los afanes de la época, se inicia una nueva etapa para la humanidad, se posibilita la realización de muchos logros que se habían mantenido en estado latente desde el siglo anterior y se tratará en los siglos siguientes de llegar a su total realización práctica.

Esa búsqueda de la felicidad, esa creencia en el progreso no desaparecen con el siglo, es prácticamente la herencia que dejan a la posteridad, una labor inconclusa en la práctica que se tratará continuamente de realizar. Sin darse cuenta, los filósofos del siglo XVIII que únicamente buscaban lo razonable nos dejaron en pie una de las ilusiones más grandes, difícilmente alcanzable: la felicidad. 


\section{La Ilustración en España}

Su participación ha sido hasta cierto punto limitada y su falta de sincronización con dicho movimiento. El siglo XVIII que se inicia con la ascensión de los Borbones al trono español, si bien no trae la influencia determinante del pensamiento francés, sin embargo trae un nuevo espíritu -no siempre acorde con la mentalidad española-, que va a tratar de dirigir las fuerzas existentes en la Península.

Este período trae un aumento de intercambios culturales (libros, correspondencia) que favorecen la difusión de teorías de moda en Europa -si bien interesantes por lo novedosas-, no siempre aceptadas ya que chocan con la mentalidad tradicional existente. La difusión del espíritu ilustrado europeo se hace en dos etapas, como lo ha señalado Sarrailh. ${ }^{6}$ La primera corresponde a las innovaciones en los aspectos científicos (Medicina, Física, Ciencias Naturales). La segunda, de la que forman parte los "ilustrados" trae la aplicación de las nuevas ideas, así como en su terminología en los demás campos del saber humano.

Es importante tener en cuenta las diferencias entre los estamentos sociales. La burguesía naciente dedicada al comercio y a las actividades de la manufactura muestra cierto interés por los cambios desde el momento en que pueden incidir en su beneficio económico. El grupo reformista trata de difundir el espíritu ilustrado europeo, si bien tienen en cuenta aquellas novedades que sean útiles y convenientes para el progreso de su país, marginando gracias a su elevado espíritu crítico, todas las ideas que puedan ser peligrosas para el mantenimiento del orden político y religioso, por los cuales muestran siempre cierto respeto. Ellos consideran a la cultural como la panacea universal para los males que sufre España puesto que "...crea y desarrolla la felicidad del pueblo"7 y gracias a ella podían dominar a la naturaleza. Cultura, por lo tanto, utilitaria y que debe además ser dirigida por el Estado. Este grupo limitado en número pero de gran calidad encuentra mayor oposición a sus planes que en otros

\footnotetext{
6 Jean Sarrailh, La España Ilustrada de la segunda mitad del siglo XVIII.

7 Jean Sarrailh, op. cit., p. 167.
}

Bol. Acad. peru. leng. 47(47), 2009 
países, debido a lo que Maravall considera mayor articulación existente entre poder real y señorial.

Al analizar el Diccionario de autoridades, publicado a partir de 1726, dentro del contexto cultural específico del siglo XVIII, advertimos en primer lugar, el interés que existe en la educación de la época por el aprendizaje de la lengua nacional así como también de las lenguas extranjeras. Pero, también dentro de otro aspecto ligado a la cultura de la época: el interés por los resúmenes, al igual que por las obras especializadas, breviarios, compendios y diccionarios. "Si se hiciera la historia de estos últimos habría que señalar el cambio progresivo de su contenido: en el renacimiento diccionarios de lenguas antiguas, en el siglo XVII de lenguas nacionales para uso de los particulares, luego diccionarios históricos y críticos. Pero se pedían de otras clases sustanciales: artes, comercio, geografía y se deseaba uno que contuviera todo lo demás. Pesado y macizo pero universal". 8

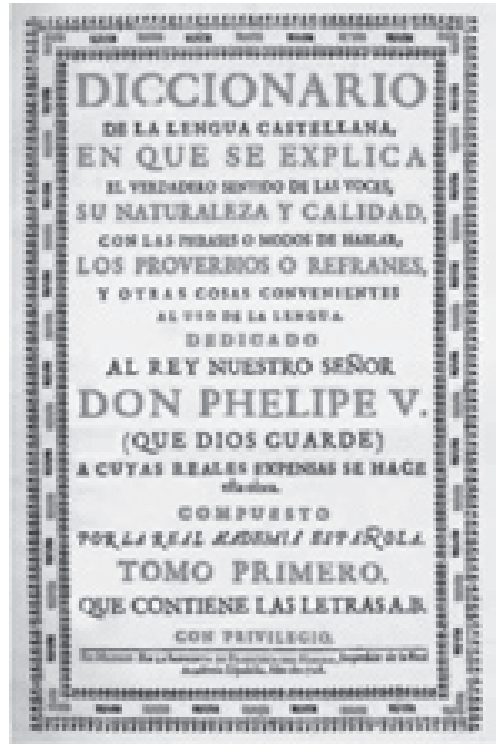

$8 \quad$ Paul Hazard, op.cit., p. 566. 


\section{BIBLIOGRAFÍA}

BARRIÊRE, Paul. La vida intelectual en Francia desde el siglo XVI hasta la época contemporánea. México, Editorial UTEHA, 1963.

CHARTIER, Roger. Espacio público, crítica y desacralización en el siglo XVIII. Barcelona, Gedisa, 2003.

GOULEMOT, Jean-Marie y LAUNAY, Michel. El siglo de las Luces. Madrid, Ediciones Guadarrama, 1969.

FLÓREZ, Gloria Cristina. "La influencia de la ideología europea del siglo XVIII en El Mercurio Peruano". Tesis para optar el grado de doctor en Historia, Lima, PUCP, 1975 (inédita).

HAMPSON, Norman. Histoire de la pensée européenne, Le siêcle des Lumiêres. Paris, Éditions du Seuil, 1972.

HAZARD, Paul. El pensamiento europeo en el siglo XVIII. Madrid, Ediciones Guadarrama, 1958.

MELCHIOR BONNET, Ch. Les Pouvoirs Absolus en Les Grands Tournants de l'histoire. Paris, Editions Tallandier, 1970.

POMEAU, René. La Europa de las luces. Cosmopolitismo y unidad europea en el siglo XVIII. México, Fondo de Cultura Económica, 1988 .

REAU, Louis. La Europa francesa en el siglo de las Luces. México, Editorial UTEHA, 1961.

SARRAILH, Jean. La España ilustrada en la segunda mitad del siglo XVIII. México, Fondo de Cultura Económica, 1957.

STAROBINSKI, Jean. L'invention de la liberté. Genève, Editions Skira, 1964.

Bol. Acad. peru. leng. 47(47), 2009 


\section{Correspondencia:}

Gloria Cristina Flórez

Docente de la Facultad de Ciencias Sociales de la Universidad Nacional Mayor de San Marcos.

Correo electrónico: catedraedt@yahoo.com 